\title{
Frequency dependence of electroluminescence measurement in LDPE.
}

\author{
BANI, N.A., ABDUL-MALEK, Z., MOHD ARIS, S.A., JALIL, S.Z.A., \\ MUHTAZARUDDIN, M.N., MAD KAIDI, H., RAHMAN, S.A.S.A., \\ MUHAMMAD-SUKKI, F., MAS'UD, A.A., ABU-BAKAR, S.H. and ARDILLA \\ REY, J.A.
}




\title{
Frequency Dependence of Electroluminescence Measurement in LDPE
}

\author{
Nurul Aini Bani ${ }^{1}$, Zulkurnain Abdul-Malek ${ }^{2}$, Siti Armiza Mohd Aris ${ }^{3}$, Siti Zura A. Jalil ${ }^{4}$, \\ Mohd Nabil Muhtazaruddin ${ }^{5}$, Hazilah Mad Kaidi ${ }^{6}$, Sharipah Alwiah Syed Abd Rahman ${ }^{7}$ \\ Firdaus Muhammad-Sukki ${ }^{8}$, Abdullahi Abubakar Mas'ud", Siti Hawa Abu-Bakar ${ }^{10}$, \\ Jorge Alfredo Ardilla Rey ${ }^{11}$ \\ 1,3,4,5,6,7 UTM Razak School of Engineering and Advanced Technology, Universiti Teknologi Malaysia, \\ Kuala Lumpur, Malaysia \\ ${ }^{2}$ Institute of High Voltage and High Current (IVAT), Universiti Teknologi Malaysia, Johor, Malaysia \\ ${ }^{8}$ School of Engineering, Robert Gordon University, Aberdeen, Scotland, United Kingdom \\ ${ }^{9}$ Department of Electrical and Electronic Engineering Technology, Jubail Industrial College, Saudi Arabia \\ ${ }^{10}$ School of Engineering \& Built Environment, Glasgow Caledonian University, Glasgow, United Kingdom \\ ${ }^{10}$ Universiti Kuala Lumpur British Malaysian Institute, Gombak, Selangor, Malaysia \\ ${ }^{11}$ Departamento de Ingeniería Eléctrica, Universidad Técnica Federico Santa Maria, Santiago de Chile
}

\begin{tabular}{l} 
Article Info \\
\hline Article history: \\
Received Jan 24, 2017 \\
Revised Apr 5, 2017 \\
Accepted May 1, 2017 \\
\hline
\end{tabular}

\section{Keyword:}

Electrical treeing

Electroluminescence

Low density polyethylene

Partial discharge

\begin{abstract}
A good insulator for high voltage cable has low dielectric loss, reasonable flexibility and thermo-mechanically stable. However, prolonged application of electrical stresses on the cable will degraded the cable; physically and morphologically. Electrical degradation in high voltage cable can be detected using electroluminescence (EL) method. Electroluminescence is a phenomenon that occurs when the atoms of a material are being excited due to the application of and external high electrical stresses. There are several external factors that affect the behaviour of electroluminescence emission such as, applied voltage, applied frequency, ageing of material and types of materials. . In this paper, the EL measurement is employed to determine the effect of applied frequency on virgin LDPE at fixed and varying applied voltage. It can be observed that EL emission increases as applied frequency increases with increasing voltage applied. However, interesting EL behaviour is observed when varying frequency is applied from $10 \mathrm{~Hz}$ to $100 \mathrm{~Hz}$.
\end{abstract}

Copyright $@ 2017$ Institute of Advanced Engineering and Science. All rights reserved.

\section{Corresponding Author:}

Nurul Aini Bani,

UTM Razak School of Engineering and Advanced Technology,

Universiti Teknologi Malaysia,

Jalan Sultan Yahya Petra, 54100 Kuala Lumpur, Malaysia.

Email: nurulaini.kl@utm.my

\section{INTRODUCTION}

Electrical degradation of high voltage cable is one of the biggest challenges faces by electrical provider world wide. Defects during manufacturing such as poor adhesion, voids and inclusion in the cable are some of the possible factors of initiating degradation and ageing processes in polymeric insulating material. Prolonged degradation will eventually resulted in electrical breakdown assisted by the formation of electrical treeing and partial discharges in the bulk of the cable. Numerous investigations have been conducted by researchers to observe the behaviour and effect of electrical breakdown [1]-[2]. Electrical treeing and partial discharges are said to be closely related to the behaviour of mobile and trapped charges in polymeric material [3]-[4]. The energy dissipation of these charges when subjected to high external field can be measured using a non-destructive measurement know as electroluminescence (EL). EL imaging captures the light emission of visible photons released during the interaction between both charges; namely the 
injection and recombination of charge carriers of opposite polarity into the bulk of the insulating material. Several studies concluded that EL measurement can be used as an indicator for electrical degradation in polymeric insulating material [5]-[6].

However, the characteristics of the EL emission can be affected by several factors such as applied voltage, applied frequency, ageing material and types of material used in a particular study. The characteristics of EL phenomenon in virgin and thermally aged low density polyethylene (LDPE) at varying applied voltage has been discussed elsewhere [7]. It was found that EL intensity increases with increasing applied voltage for both virgin and thermally aged LDPE. This is consistent with many other studies [8]-[9]. Ageing temperature also influence the EL emission with LDPE aged at lower temperature $(310 \mathrm{~K})$ has higher EL intensity than that of higher temperature $(350 \mathrm{~K})$ [7]. However, very limited studies were conducted on the effects of frequency of applied voltage on the behavior of EL emission. A study by [10] on LDPE subjected to applied frequency of $60 \mathrm{~Hz}$ to $10 \mathrm{kHz}$ under divergent field configuration, found that the EL intensity decreases for increasing frequencies. For LDPE of $50 \mu \mathrm{m}$ thickness subjected to frequencies in the range of $10^{-2} \mathrm{~Hz}$ to $10^{2} \mathrm{~Hz}$ under uniform field configuration, there is a constant increase in EL counts per cycle for increasing frequency for applied voltage below $80 \mathrm{kV} / \mathrm{mm}$ as obtained by [11]. At higher voltage levels, there is a drastic decreased as frequency increases. A mathematical model has been developed relating the light emission data and the factors contributing to it through the aid of Dimensional Analysis method [12]. This section will present and discuss the influence of the frequency of applied voltage on the characteristics of EL emission for LDPE samples of $100 \mu \mathrm{m}$ thickness under uniform field configuration subjected to varying frequencies ranges from $10 \mathrm{~Hz}$ to $100 \mathrm{~Hz}$. The effect of frequency will be observed at fixed and varying applied voltage.

\section{RESEARCH METHOD}

The EL measurement is collected from an additive-free virgin low density polyethylene (LDPE) of $100 \pm 5 \mu \mathrm{m}$. To fit the sample holder, samples are cut into $60 \mathrm{~mm}$ x $60 \mathrm{~mm}$ squares. The sample is metallized with about $20 \mathrm{~nm}$ thick of semi-transparent gold layer on both sides of the sample using gold-sputtering process with sputter time of 2.5 minutes on each side. This produces a $35 \mathrm{~mm}$ diameter of gold electrode that will provide reasonable electrode conduction for the uniform field configuration. A silicon rubber is applied around the edge of the gold electrodes in order to reduce the presence of discharges. For EL measurement, the uniform field configuration is shown in Figure 1 using a plane and grounded ring electrodes. Sample is sandwiched between these two electrodes and placed inside a vacuum chamber. The vacuum chamber is filled with 1 bar of dry Nitrogen to avoid corona discharges. The detection system utilizes a Peltier cooled electron multiplying charge coupled device (EMCCD) camera and is connected to high voltage amplifier and function generator. For EL experiment, phase-resolved measurements is applied which involve 100 sets of $1000,2.168 \mathrm{~ms}$ exposures. The measurement is synchronized with the applied field using the zero crossing point trigger. Two experiments are conducted to observe the frequency dependence of EL intensity. First experiment involves subjecting samples to varying applied voltage from $3 \mathrm{kVp}$ to $6 \mathrm{kVp}$ at fixed frequency of $20 \mathrm{~Hz}, 50 \mathrm{~Hz}$ and $80 \mathrm{~Hz}, \mathrm{AC}$ sinewave. Voltage is kept constant for 4 minutes and then increased at $1 \mathrm{kV}$ peak steps. Measurements are taken at each step. In second experiment, samples are subjected to varying applied frequency from $10 \mathrm{~Hz}$ to $100 \mathrm{~Hz}, \mathrm{AC}$ sinewave at fixed voltage of $6 \mathrm{kVp}, 7 \mathrm{kVp}$ and $8 \mathrm{kVp}$. Frequency is kept constant for 4 minutes and then increased at $10 \mathrm{~Hz}$ steps. Measurements are taken at each step. All experiments are conducted at room temperature.

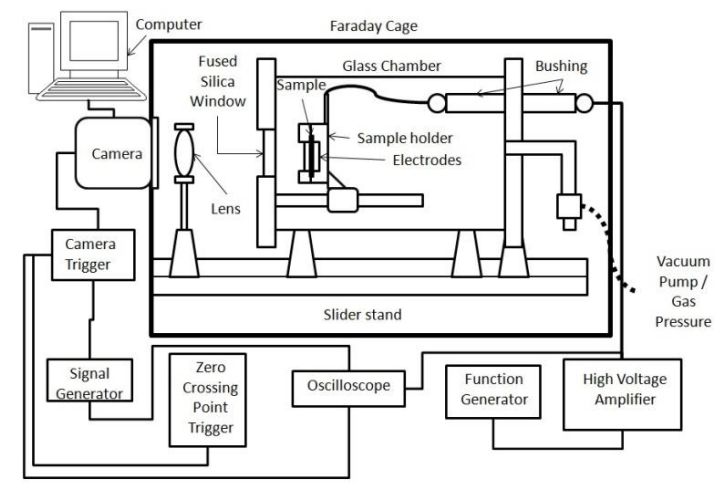

Figure 1. Experimental setup for EL measurement on LDPE samples 


\section{RESULTS AND ANALYSIS}

In this section, the EL results obtained for both experiments are discussed.

\subsection{Varying applied voltage at fixed frequency}

In this experiment, samples are subjected to varying applied voltage from $3 \mathrm{kVp}$ to $6 \mathrm{kVp}$ at fixed frequency of $20 \mathrm{~Hz}, 50 \mathrm{~Hz}$ and $80 \mathrm{~Hz}, \mathrm{AC}$ sinewave. Figure 2 shows the intensity of EL peak for each frequency of $20 \mathrm{~Hz}, 50 \mathrm{~Hz}$ and $80 \mathrm{~Hz}$ at every voltage step emitted during the first and third quadrant of the applied voltage. The EL intensity is lesser for lower applied frequency at increasing applied voltage. This result is supported with the result in Figure 3. Figure 3 shows the average value of EL intensity for applied frequency of $20 \mathrm{~Hz}, 50 \mathrm{~Hz}$ and $80 \mathrm{~Hz}$ from $3 \mathrm{kVp}$ to $6 \mathrm{kVp}$. Evidently there is a direct relationship between average EL intensity and applied frequency. As applied voltage increases, the average EL intensity increases with increasing applied frequency. At $80 \mathrm{~Hz}$, the average EL intensity increases drastically from $3 \mathrm{kVp}$ to 6 $\mathrm{kVp}$. However at $20 \mathrm{~Hz}$, the increment is very linear with only small increases while there is a steady increased at applied frequency of $50 \mathrm{~Hz}$. This direct relationship of EL behavior is expected since EL is controlled by the number of recombination of injected and trapped charges of opposite polarity. At lower frequency, the voltage during the first and third quadrant of the cycle stays above the threshold level of EL emission for a longer time than the higher frequency. Therefore, less number of charges is injected at the polymer interface and thus less chances of charge recombination. For example, during the acquisition time of 4 minutes or $240 \mathrm{~s}$, applied frequency of $50 \mathrm{~Hz}$ produces 12,000 AC cycles while applied frequency of $80 \mathrm{~Hz}$ produces 19,200 AC cycles. This means that the former has 0.625 times lesser AC cycles than the latter in $240 \mathrm{~s}$ of acquisition time. As explained by bipolar recombination model in [13], when sample is subjected to external electrical stress, charges are injected into the polymer at every first and third quadrant of the AC cycles. Therefore less charges is injected during applied frequency of $50 \mathrm{~Hz}$ than at $80 \mathrm{~Hz}$ since the AC cycles of the former appears 0.625 times lesser than the latter.
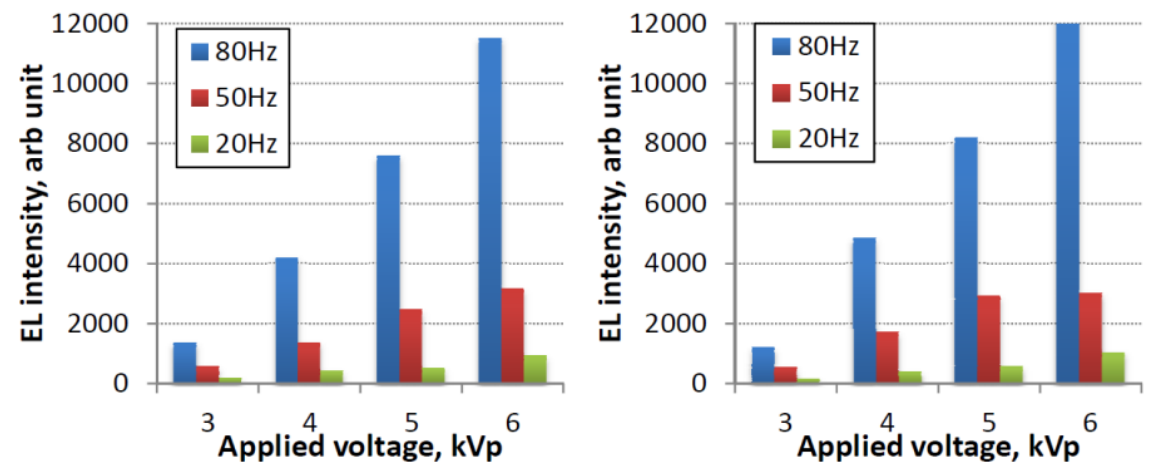

Figure 2. Peak of EL intensity at each voltage level for (a) first quadrant and (b) third quadrant for all samples

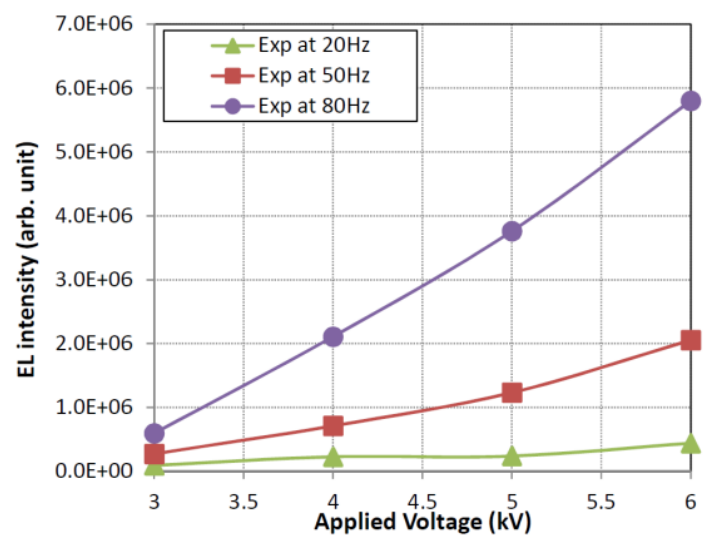

Figure 3. The average value of EL intensity for applied frequency of $20 \mathrm{~Hz}, 50 \mathrm{~Hz}$ and $80 \mathrm{~Hz}$ at all voltage steps 


\subsection{Varying frequency at fixed applied field}

In this section, virgin samples are subjected to applied frequency of $10 \mathrm{~Hz}$ to $100 \mathrm{~Hz}$ at a constant applied voltage of $5 \mathrm{kVp}, 6 \mathrm{kVp}$ and $7 \mathrm{kVp}$. Figure 4 shows the average EL intensity of LDPE samples at increasing applied frequency from $10 \mathrm{~Hz}$ to $100 \mathrm{~Hz}$ when subjected to applied field of $5 \mathrm{kVp}, 6 \mathrm{kVp}$ and 7 $\mathrm{kVp}$. It can be observed that the EL intensity behaviour for all voltages is indistinctive. However, there are some visible patterns that occurred at $20 \mathrm{~Hz}, 60 \mathrm{~Hz}$ and $90 \mathrm{~Hz}$. The EL intensity had a drastic increase at 20 $\mathrm{Hz}$ after a low intensity at $10 \mathrm{~Hz}$ followed by a dropped at $30 \mathrm{~Hz}$ for all voltage applied. This pattern is repeated at $60 \mathrm{~Hz}$ and $90 \mathrm{~Hz}$ where the EL intensity had an evident increased at both frequencies followed by a dropped at subsequent frequency of $70 \mathrm{~Hz}$ and $100 \mathrm{~Hz}$ respectively. EL intensity is the lowest at $100 \mathrm{~Hz}$ for all voltages. It is assumed that at the early stage of the experiment i.e. at $10 \mathrm{~Hz}$, the injected charges would first fill the surface states. As the frequency is increased to $20 \mathrm{~Hz}$, the number of charge injection increases thus higher number of the charge recombination is obtained. This is illustrated with the high EL intensity at $20 \mathrm{~Hz}$. The dropped of EL intensity at $30 \mathrm{~Hz}$ is the result of high charge recombination rate that occurs during the preceded frequency. Figure 5 shows the shift of phase angles of sample at all applied frequency for first and third quadrant. Likewise, there is no significant pattern that can be observed from this experiment and hence no relationship can be deduced between phase angle and increasing applied frequency. The variations are scattered for both the first and third quadrant.

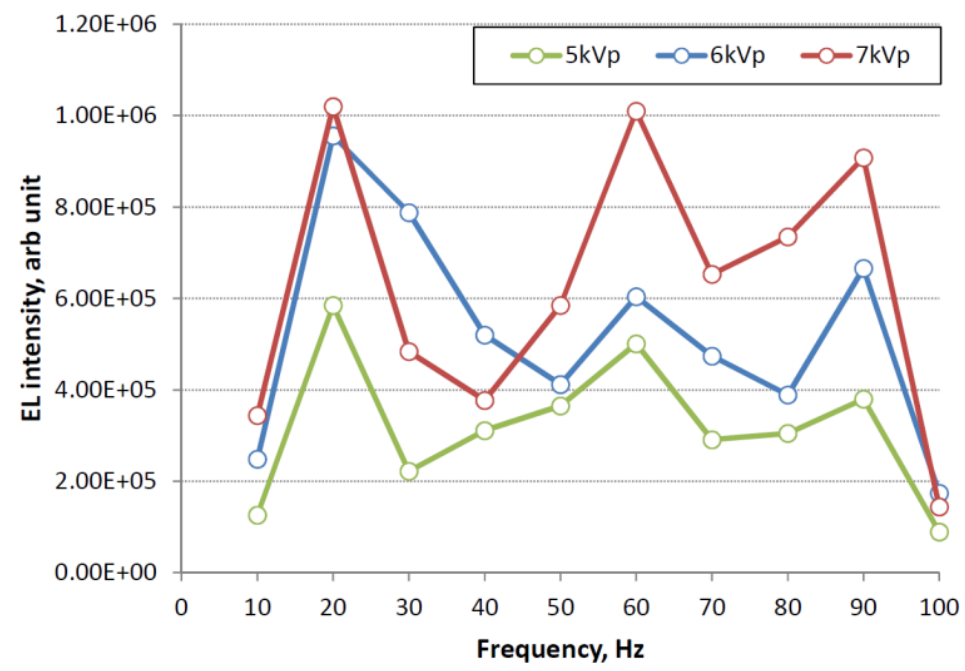

Figure 4. The average value of EL intensity for applied field of $5 \mathrm{kVp}, 6 \mathrm{kVp}$ and $7 \mathrm{kVp}$ at all frequencies

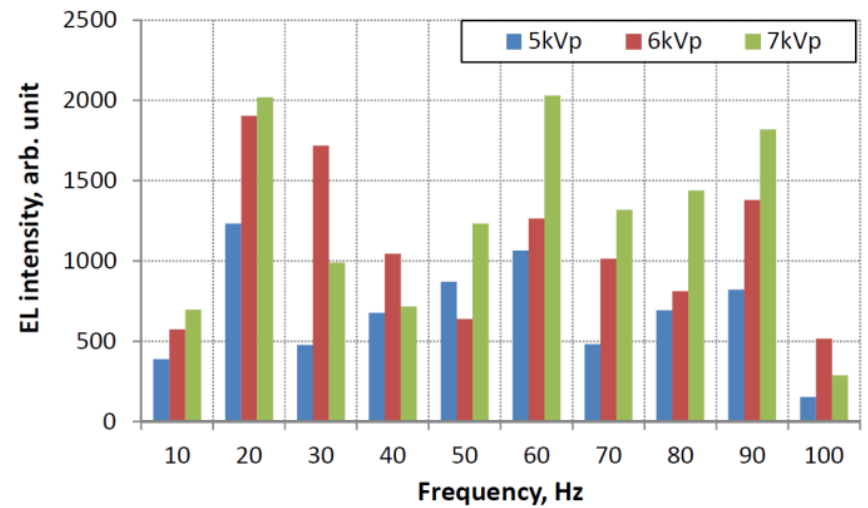

(a) 


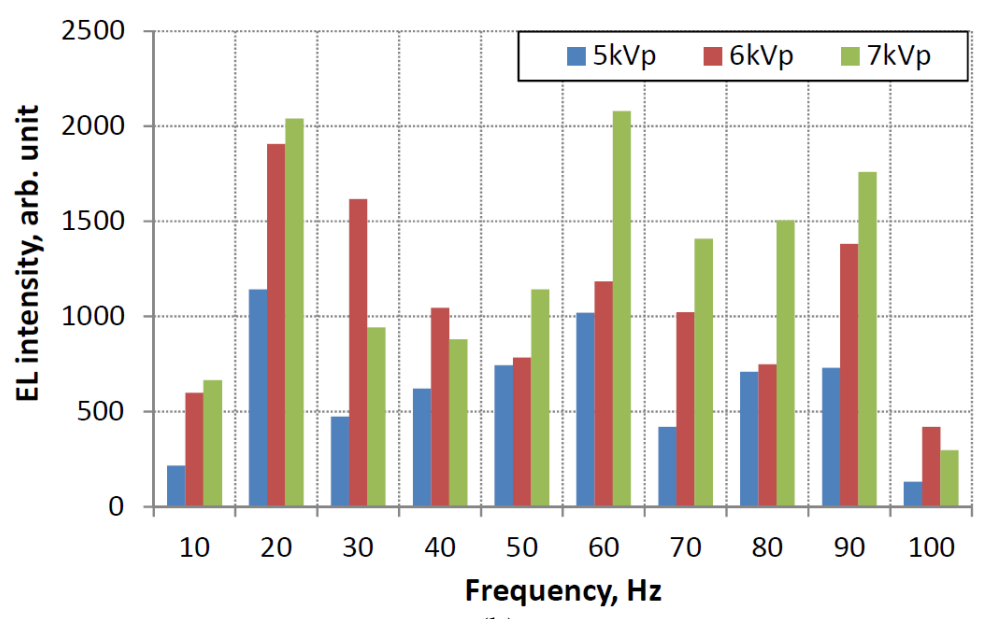

(b)

Figure 5. Peak of EL intensity for applied field of $5 \mathrm{kVp}, 6 \mathrm{kVp}$ and $7 \mathrm{kVp}$ at all frequencies for (a) first and (b) third quadrant

\section{CONCLUSION}

It can be observed that EL phenomenon behaves differently for both EL experiments. The value of EL intensity is also different for both EL experiments eventhough the same of frequency is used due to the nature of the accumulation and recombination of trapped and mobile charges in the material. For EL measurement in varying applied voltage at constant frequency, a direct relationship is obtained between EL intensity and applied frequency where higher applied frequency resulted in higher EL intensity. For EL measurement in varying frequency at constant applied voltage, there is no specific pattern or trend that can be concluded from the experimental data. However, it was observed that EL emission reached its peak at $20 \mathrm{~Hz}$, $60 \mathrm{~Hz}$ and $90 \mathrm{~Hz}$. In both experiments, the EL intensity is greatly influenced by the number of charge and recombination in the material.

\section{ACKNOWLEDGEMENTS}

The author would like to thank Ministry of Higher Education (MOHE), Malaysia and Universiti Teknologi Malaysia (UTM) (Research cost centre no. Q.K130000.2540.11H28) for funding this project. The first author wishes to express her deepest gratitude to all staff at the Tony Davies High Voltage Laboratory for their guidance and support throughout the research undertaken at University of Southampton.

\section{REFERENCES}

[1] Abd Allah M. A. A, et al., "Effect of Coating of Earthed Enclosure and Multi-contaminating Particles on Breakdown Voltage inside Gas Insulated Bus Duct," International Journal of Electrical and Computer Engineering (IJECE), vol/issue: 4(4), pp. 471-485, 2014.

[2] Rouini A., et al., "Prediction the AC Breakdown Voltage in Point/Plane Air Gaps with Barrier Using Design of Experiments," International Journal of Electrical and Computer Engineering (IJECE), vol/issue: 12(12), pp. 80338041, 2014.

[3] L. A. Dissado, et al., "Discussion of Space-Charge Life Model Features in DC and AC Electrical Aging of Polymeric Materials," IEEE 1997 Annual Report Conference on Electrical Insulation, vol/issue: 1(6), pp. 36-40, 1997.

[4] L. A. Dissado, et al., "The Incorporation of Space Charge Degradation in the Life Model for Electrical Insulating Materials," IEEE Transactions on Dielectrics and Electrical Insulation, vol/issue: 2(6), pp. 1147-58, 1997.

[5] A. M. Ariffin, et al., "Comparison of Electroluminescence Phenomenon in LDPE, PET and PEN under the Application of High Electrical Stress," Annual Report Conference on Electrical Insulation and Dielectric Phenomena, pp. 260-263, 2006.

[6] G. Teyssedre, et al., "Charge distribution and electroluminescence in cross-linked polyethylene under dc field," Journal of Physics D: Applied Physics, pp. 2830 - 2844, 2001.

[7] N. A. Bani, et al., "Characteristics of electroluminescence phenomenon in virgin and thermally aged LDPE," AIP Conference Proceedings, vol. 1674, pp. 020005, 2015. 
[8] A. Mohd Ariffin, et al., "Determining the Occurrence of Electroluminescence in Polymeric Materials with Respect to the Applied Alternating Electrical Stress," IEEE International Conference on Solid Dielectrics, pp. 703-706, 2007.

[9] D. Mills, et al., "Comparison between the Electroluminescence and Space Charge of Ultraviolet and Thermally Aged Low Density Polyethylene," Annual Report Conference on Electrical Insulation and Dielectric Phenomena (CEIDP), pp. 1-4, 2010.

[10] N. Shimizu, et al., "Space Charge Behavior and Luminescence Phenomena in Polymers at 77 Kelvin," IEEE Transactions on Electrical Insulation, vol/issue: 14(5), pp. 256-263, 1979.

[11] L. Cissé, et al., "Influence of Frequency, Electrode Material and Superimposed DC on AC Electroluminescence in Polymer Films," IEEE Transactions on Dielectrics and Electrical Insulation, vol/issue: 9(1), pp. 124-129, 2010.

[12] N. A. Bani, et al., "Modelling the Effect of Applied Voltage and Frequency on Electroluminescence in Polymeric Material," International Journal of Electrical and Computer Engineering, vol/issue: 6(3), pp. 1375-1384, 2016.

[13] J. M. Alison, et al., "Dynamic Bipolar Charge Recombination Model for Electroluminescence in Polymer Based Insulation during Electrical Tree Initiation,” Journal of Physics D. (Applied Physics), vol/issue: 28(8), pp. 1693$1701,1995$.

\section{BIOGRAPHIES OF AUTHORS}
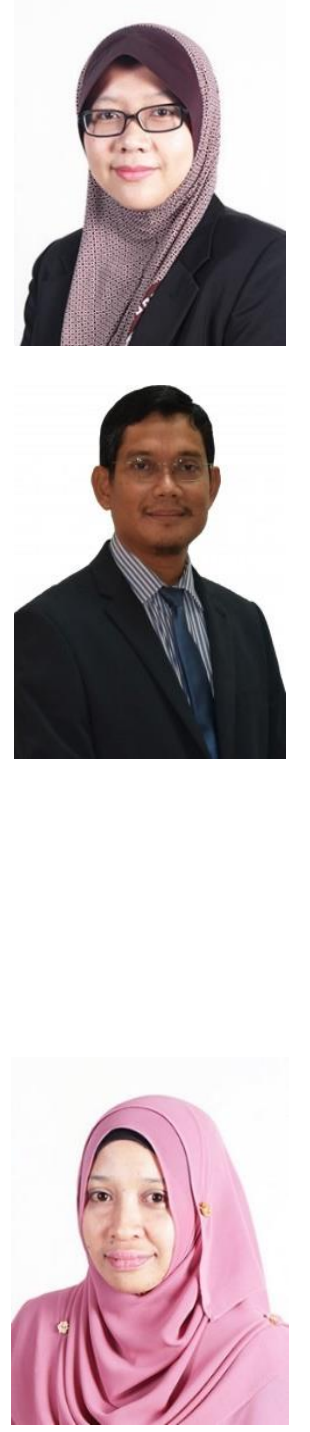

Dr Nurul Aini Bani received her M.Eng degree in Electrical Engineering from University of Southampton, UK in 2006 where she received two academic awards for outstanding academic performance. She received her PhD degree in Electrical Engineering from Universiti Teknologi Malaysia, Malaysia in 2016. Her research interests include polymeric insulation material, space charge measurement, high voltage cable, renewable energy and rehabilitation engineering. She has authored and co-authored several papers in various technical journals and conference proceedings. She is now a lecturer in the Department of Engineering, UTM Razak School of Engineering and Advanced Technology (RSEAT).

Prof. Dr. Z. Abdul-Malek received the B.E. degree in electrical and computer systems from Monash University, Melbourne, Australia, in 1989, the M.Sc. degree in electrical and electromagnetic engineering with industrial applications from the University of Wales Cardiff, Cardiff, U.K., in 1995 and the Ph.D. degree in high voltage engineering from Cardiff University, Cardiff, U.K., in 1999. He was a Lecturer with Universiti Teknologi Malaysia (UTM) for 25 years, where he is currently a Professor of High Voltage Engineering with the Faculty of Electrical Engineering. He is currently the Director of the Institute of High Voltage and High Current (IVAT), UTM. He has published two books, and has authored and co-authored more than 100 papers in various technical journals and conference proceedings. His research interests include high-voltage instrumentation, lightning protection, detection and warning systems, partial discharges, nanodielectrics, and condition monitoring of power equipment. Dr. AbdulMalek is actively involved in many national committees. He is the Chairman, Working Group on High-Voltage and High-Current Test Techniques. He is also a member of IEC Certification Body Management Committee, Technical Committee on High Voltage Power Transmission, Working Group on High Voltage Switchgear and Controlgears, Technical Working Group for Electrical Testing, and Department of Standards IEC 17025 Technical Assessors. He is a member of the Power and Energy Society, Dielectrics and Electrical Insulation.

Dr Siti Armiza was born in Alor Setar, Kedah, Malaysia in 1975. She graduated from Universiti Teknologi Malaysia (UTM) during her bachelor degree and master degree. She obtained her B. Eng. (Hons) in Electrical Engineering (Microelectronics) in 1998 and her M. Eng. in Electrical Engineering in 2001. She has also received her PhD in 2016 from Universiti Teknologi MARA, Selangor, Malaysia. She is currently a senior lecturer in UTM Razak School of Engineering and Advanced Technology, Universiti Teknologi Malaysia, Kuala Lumpur. Her current research interests include Feature Extraction, EEG Classification, EEG Clustering, EEG-Psychological related, EEG Signal Processing, Bio-signals Processing, Fuzzy, ANN, Computational Intelligence. 

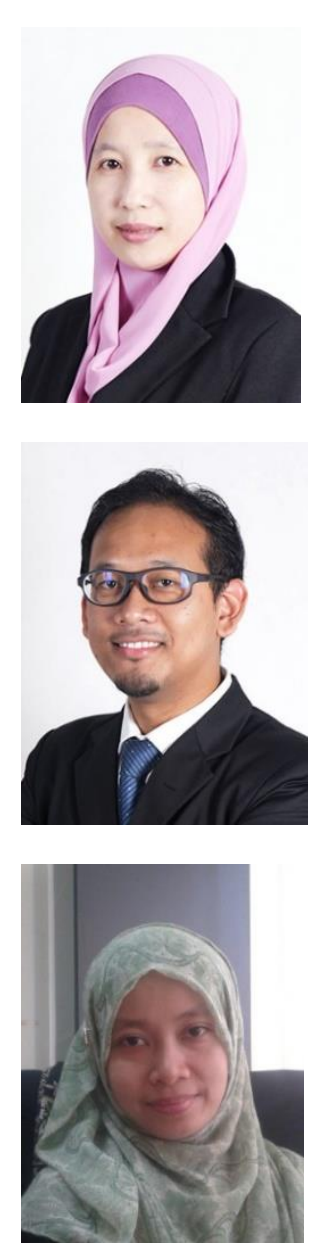

Dr Hazilah Mad Kaidi was born in Klang Selangor, Malaysia in 1981. She obtained his Diploma in Electrical Eng. Communication (2002), B. Eng. (Hons) in Electrical Eng. Telecommunication (2006) from Universiti Teknologi Malaysia (UTM) and M.Sc. in Telecommunication and Information Eng.(2008) from Universiti Teknologi MARA (UiTM) Malaysia. She also received a PhD from UTM in Electrical Eng. (2015). She currently a senior lecturer in Universiti Teknologi Malaysia (UTM) Kuala Lumpur in UTM Razak School of Engineering and Advanced Technology. Her current research interests include information theory, Channel coding and propagation in wireless communication system.

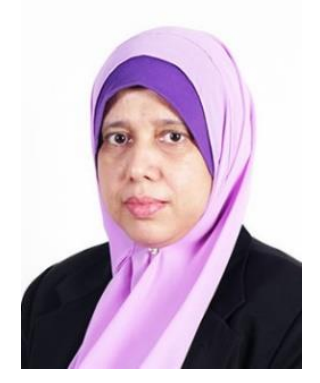

Sharifah was born in Batu Pahat, Johor, Malaysia. She obtained her Bachelor Degree in Mathematics from Trent University, Peterborough, Canada in 1987 and MSc. (Mathematics) from Universiti Teknologi Malaysia (UTM), Johor Bahru, Malaysia in 2004. She then received her PhD in 2013 from Universiti Kebangsaan Malaysia (UKM), Bangi, Selangor, Malaysia. Currently she is a senior lecturer in Universiti Teknologi Malaysia, Kuala Lumpur. Her current research interests including applied mathematics and biomechanics.

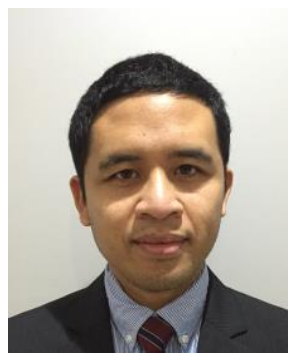

Dr Firdaus Muhammad-Sukki received his MEng degree in Electrical and Electronic Engineering from Imperial College, London in 2006 under the Yayasan TM scholarship. In 2009, he received studentship awards from Glasgow Caledonian University (GCU), Scottish Funding Council (SFC) and Yayasan TM to pursue his postgraduate study in Glasgow Caledonian University from which he obtained his $\mathrm{PhD}$ in 2013. His research interest is in solar energy, particularly in terms of designing optical solar concentrators to create a low cost solar photovoltaic system and renewable energy policies. He has a number of papers in high impact factor journals, as well as presenting in a number of conferences related to his area. Prior to joining the academia, he was a communication engineer in Malaysia's largest telecommunication company. He was in charge of the leased line servers for Malaysia's network and was involved in major projects related to the telecommunication while holding the post. 

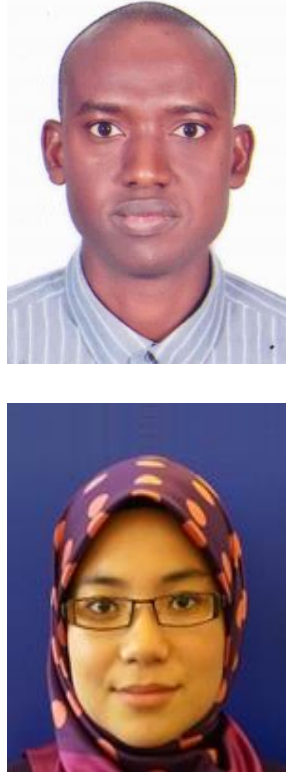

Dr Abdullahi Abubakar Mas'ud was born in Kano, Nigeria in 1975. He received his BEng (Hons) degree in Electrical Engineering in 1999 and his Msc in Electronics and Communication in 2006, both from Ahmadu Bello University, Zaria, Nigeria. He also received a PhD in High voltage Engineering in 2013 from the Glasgow Caledonian University, Scotland, UK. In 2002 he became an assistant lecturer in the Faculty of Engineering at the Ahmadu Bello University, Zaria, Nigeria. In 2013 he joined Jubail Industrial College, Saudi Arabia, and is currently an Assistant Professor in the Department of Electrical and Electronic Engineering. He has more than 10 years of teaching experience. His research interests lie in the fields of communication systems, renewable energy, high voltage partial discharge and nanotechnology. He has published numerous research papers in international conferences and journals. Dr Abdullahi A Mas'ud is a Member of the IET and a registered Engineer (COREN) Nigeria.

Dr Siti Hawa Abu-Bakar obtained her BEng in Information Systems Engineering from Imperial College, London in 2006 under the MARA scholarship. In 2007, she joined Prokhas Sdn. Bhd., a wholly-owned company under the Ministry of Finance Malaysia as the Executive Trainee. From 2008 onwards, she becomes a unit trust consultant for Public Mutual Bhd. In 2011, she was awarded studentships from GCU and Scotland's Energy Technology Partnership (ETP) to pursue her post graduate study in solar technology from which she obtained her $\mathrm{PhD}$ in 2016. Dr AbuBakar is an associate of the City and Guilds, London (ACGI). Her interests include solar PV, solar thermal, financial planning and investment analysis.

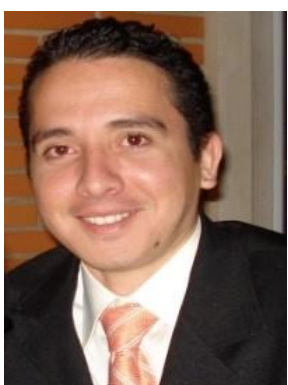

Dr Jorge Alfredo Ardila Rey was born in Santander, Colombia, in 1984. He received the B.Sc. degree in mechatronic engineering from Universidad de Pamplona, Pamplona Colombia in 2007. He received the Specialist Officer degree in Naval Engineering from Escuela Naval Almirante Padilla, Cartagena, Colombia in 2008. He received the M.Sc. and Ph.D. degrees in electrical engineering from Universidad Carlos III de Madrid (UC3M) in 2012 and 2014, respectively. He was an Automatic Control Engineer of ARC Almirante Padilla from 2008 to 2010. From 2010 to 2014, he worked in the Department of Electrical Engineering and the High-Voltage Research and test Laboratory (LINEALT) at UC3M. He is currently working as a Professor at the Department of Electrical Engineering of Universidad Técnica Federico Santa María at Santiago of Chile. His research interests include partial discharges, insulation systems diagnosis and instrumentation and measurement techniques for high frequency currents. 